\title{
Does the Canadian Emergency Department Triage and Acuity Scale identify non-urgent patients who can be triaged away from the emergency department?
}

\author{
Les Vertesi, MD, MHSc
}

\begin{abstract}
Introduction: Non-urgent visits comprise a significant proportion of visits to most emergency departments (EDs). Given the severe overcrowding issues faced by many EDs, the use of the Canadian Emergency Department Triage and Acuity Scale (CTAS) to identify patients who could be managed elsewhere seems to be an obvious way to reduce the pressure on the ED and "solve" the overcrowding problem.

Objective: To quantify the resource implications, in terms of stretcher use and waiting times, related to non-urgent patient visits and to estimate the potential impact on ED flow of redirecting these patients to alternate primary care settings.

Methods: Retrospective database audit in an urban referral hospital ED. For this study, patients triaged as either CTAS Levels IV or V were considered "non-urgent."

Results: Non-urgent patients comprised $30 \%$ of ED visits, but less than $5 \%$ of all those needing stretchers, along with their associated nursing resources. The longer waits consisted almost entirely of waits for available stretchers and would therefore have remained essentially unaffected. In spite of being labelled "non-urgent" by CTAS criteria, 7.3\% of all patients requiring admission came from this group.

Conclusions: Non-urgent patients consume a small fraction of the ED stretchers and acute-care resources; therefore, strategies aimed at diverting non-urgent patients are unlikely to improve access for more urgent patients. Using the CTAS to identify patients for diversion away from the ED is measurably unsafe and will lead to inappropriate refusal of care for many patients requiring hospital treatment.
\end{abstract}

Key words: emergency department overcrowding; CTAS; Canadian Emergency Department Triage and Acuity Scale; emergency department management

\begin{abstract}
RÉSUMÉ
Introduction : Les consultations non urgentes représentent un pourcentage important des visites à la plupart des urgences. Compte tenu des graves problèmes d'engorgement auxquels font face beaucoup de services d'urgence, l'utilisation de l'échelle pour identifier les patients qui pourraient être pris en charge ailleurs semble constituer un moyen évident de réduire les pressions qui s'exercent sur le service d'urgence et de «régler» les problèmes d'engorgement.

Objectif : Quantifier les répercussions des consultations non urgentes sur les ressources, en ce qui concerne l'utilisation des civières et les temps d'attente et estimer l'impact que pourrait avoir sur l'achalandage des urgences le renvoi de ces patients vers d'autres milieux de soins primaires.
\end{abstract}

Associate Director of Health Research, Fraser Health Authority; Research Consultant, Institute for Health Research and Education, Simon Fraser University; Emergency Physician, Royal Columbian Hospital, New Westminster, BC

Received: Mar. 18, 2004; final submission: June 21, 2004; accepted: July 16, 2004

This article has been peer reviewed.

Can J Emerg Med 2004;6(5):337-42 
Méthodes : Vérification rétrospective de la base de données du service d'urgence d'un hôpital de référence en milieu urbain. Dans cette étude, les patients classés au triage aux niveaux IV ou $V$ de I'ETG étaient jugés «non urgents».

Résultats : Les patients dont le cas n'était pas urgent constituaient $30 \%$ des consultations à l'urgence, mais moins de $5 \%$ des patients ayant besoin d'une civière et des ressources infirmières connexes. Les temps d'attente les plus longs consistaient presque entièrement en attente pour obtenir une civière disponible et seraient donc demeurés essentiellement les mêmes. En ce qui concerne les cas qualifiés de «non urgents» selon les critères de I'ETG, 7,3\% des admissions effectuées via l'urgence provenaient de ce groupe.

Conclusions: Dans ce contexte, les cas non urgents ont consommé un pourcentage minimal des ressources en civières et en services infirmiers à l'urgence et n'ont pas contribué considérablement aux temps d'attente pour une civière. Une politique consistant à diriger les cas non urgents vers d'autres milieux de soins aurait eu pour effet de refuser ou de retarder les soins chez $7 \%$ des patients de ce groupe qui avaient besoin d'hospitalisation.

\section{Introduction}

Overcrowding and excessive delays are a serious problem in urban emergency departments (EDs), ${ }^{1-5}$ yet it is clear that many patients who seek ED care could, in hindsight, have been managed in lower acuity settings. It seems logical therefore to believe that non-urgent patients may be consuming limited ED resources and impeding access for patients who need urgent and emergent care. If this is true, then diverting non-urgent patients from EDs might help reduce delays and improve access for sicker patients. ${ }^{6-9}$

The Canadian Emergency Department Triage and Acuity Scale $(\mathrm{CTAS})^{10}$ has been extensively studied and validated in a variety of settings. ${ }^{11-13}$ CTAS triage Levels IV and $\mathrm{V}$ encompass patients with less urgent conditions for which physician assessment could perhaps be delayed. Some believe that triage levels could be used to identify patients who can be safely triaged away from the ED to other care settings. Such redirection would be beneficial if it freed up acute-care stretchers and reduced access delays for more urgent patients.

The primary objective of this study was to determine how often CTAS Levels IV and V patients occupy ED stretchers that are staffed to provide acute care, thereby preventing access for sicker patients. The secondary objective was to determine whether CTAS might be used to safely divert "inappropriate" patients away from the ED, by determining the rate of hospital admission in patients designated as CTAS Levels IV and V.

\section{Methods}

\section{Setting}

This ED administrative database review included standard utilization data from all emergency patient visits to the Royal Columbian Hospital in New Westminster, BC, for the 6-month period between Apr. 1 and Sept. 30, 2003. The Royal Columbian Hospital is an urban tertiary care and trauma referral centre that sees about 50000 visits per year, with an overall admission rate of just under $20 \%$.

\section{Patients and procedures}

New arrivals in the facility are seen initially by triage nurses trained in the use of the CTAS. Triage nurses assign a CTAS level and ED treatment location if one is available (see Fig. 1). Options for placement include an ambulant care area for patients who do not require stretchers or direct nursing care, an acute-care stretcher area (with a 1:4 nurse/patient ratio), a pediatric area with cribs, and a psychiatric interview area. Patients who arrive by ambulance and require a stretcher when none are available are held in a temporary hallway queue, on the ambulance stretcher and under the care of an emergency medical services (EMS) attendant until an appropriate acute-care stretcher is available.

\section{Data capture}

The study information was derived from the hospital's central database. All data extracted for this study were entered in real time by ED staff at the time of the patient visit. The same database is also used for routine health reporting and undergoes regular auditing. Information collected for this analysis included CTAS triage score, initial treatment area assigned by the triage nurse, waiting time to reach ED treatment location, and final disposition (admission or discharge). For the purposes of this study, patients triaged as CTAS Levels IV and V were considered "non-urgent" and those triaged as Levels I to III were considered "urgent."

\section{Outcomes}

The primary outcome was the number of non-urgent patients who were assigned to one of the staffed stretchers. 
Secondary outcomes included the frequency of hospital admission in the non-urgent triage categories.

\section{Data analysis}

Data was analyzed with MS ACCESS and Excel (Microsoft) using group proportions and percentiles for waiting times.

\section{Results}

The overall ED admission rate during the study period was $18.4 \%$, typical of the department's historical pattern. Of 23573 ED patients seen during the 6-month study period
(Table 1), 7116 (30.2\%) were classed as non-urgent (CTAS Levels IV or V). Table 1 also shows that admission rates generally correlated with CTAS triage level but that 316 of 4336 patients $(7.3 \%)$ who ultimately required admission came from the non-urgent (CTAS IV and V) triage categories.

Figure 1 illustrates patient distribution and flow during the study period. All but 179 of the 23573 visits were associated with valid entry location. These lost data (representing less than 1\%) were omitted from Figure 1 for simplicity.

Table 2 summarizes the location in the ED where urgent and non-urgent patients were placed by the triage nurses.

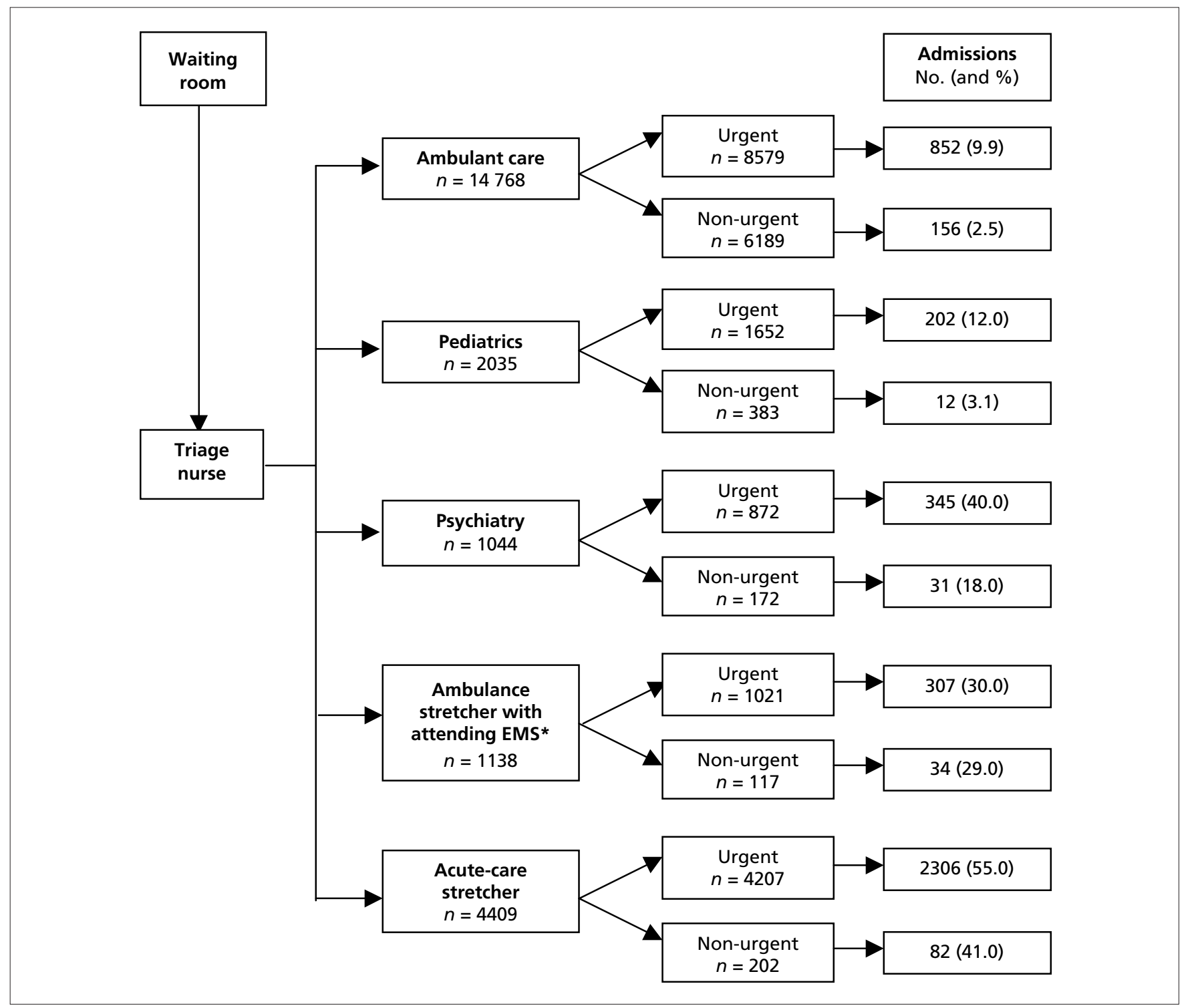

Fig. 1. Patient flow. *EMS = patients held on the ambulance stretcher and under the care of an emergency medical services (EMS) attendant until an appropriate acute-care stretcher is available. For this study, CTAS Levels IV and V were defined as "Non-urgent" and Levels I to III were defined as "Urgent." 
This table shows that 6189 (87\%) of 7116 non-urgent patients were placed in the ambulant care area (also known as "fast track"), an area with a low level of nursing staff that is not equipped to manage acutely ill patients. Non-urgent patients, including those who required admission, accounted for less than 5\% (202/4409) of the total number placed in acute-care stretchers.

Table 3 shows that the average time to placement for urgent patients requiring a stretcher was 67 minutes, compared to 43 minutes for non-urgent patients who did not need a stretcher. The same comparison using 90th percentile waiting times shows a more dramatic difference of 200 versus 100 minutes. This demonstrates that the greatest access problem and longest care delays are related to waits for acute-care stretchers.

The combined information in Table 2 and Table 3 suggests that a triage-based intervention to divert all low priority patients from the ED (at least by CTAS criteria) would have little impact on care delays and access block.

\begin{tabular}{|c|c|c|c|}
\hline $\begin{array}{l}\text { CTAS } \\
\text { level }\end{array}$ & $\begin{array}{l}\text { Total no. } \\
\text { of patients } \\
\text { assigned } \\
\text { each level }\end{array}$ & $\begin{array}{c}\text { Percentage } \\
\text { of all ED } \\
\text { visits }\end{array}$ & $\begin{array}{c}\text { No. (and \%) } \\
\text { of patients } \\
\text { admitted }\end{array}$ \\
\hline I & 293 & 1.2 & 201 (68.6) \\
\hline II & 2707 & 11.5 & $1193(44.1)$ \\
\hline III & 13457 & 57.2 & 2626 (19.5) \\
\hline IV & 6426 & 27.2 & $306(4.8)$ \\
\hline V & 690 & 2.9 & $10(1.5)$ \\
\hline Totals & 23573 & 100.0 & 4336 (18.4) \\
\hline
\end{tabular}

\section{Discussion}

The notion that non-urgent patient diversion will help solve the access block created by ED overcrowding remains widespread, even though it is unsupported by data. This study suggests that using CTAS as a tool to divert non-urgent patients away from the ED would reduce the demand on acute-care stretchers in the ED by only $4.6 \%$ (202/4409) and would lead to denial or delay of care for $7.3 \%$ of patients who required hospitalization. This should stimulate a rethink of the safety and effectiveness of such strategies. In a hospital that admits approximately 10000 patients per year, this $7.3 \%$ "miss rate" would lead to inappropriate refusal of care for 730 patients every year. At least some of these patients would experience a worsening of their condition and face the possibility of a major adverse event or a more complicated and prolonged in-hospital stay. Even if no patient sustained any actual harm, the added delay in care and duplication of services has a financial cost that would quickly exceed the negligible savings created by non-urgent patient diversion.

These findings do not reflect a local anomaly; previous literature suggests that triage categorization alone "misses" approximately 5\% of patients who require hospital admission. ${ }^{8,14,15}$ Although CTAS does correlate with acuity and admission rates, the non-urgent Levels IV and V still generated a significant number of admissions. This is in part because the triage scales were never intended as a workload or illness severity tool, but rather as means to ensure proper time from entry until the patient is seen by a physician. In spite of this, CTAS is often used as a surrogate for illness severity and, in the absence of other more valid measures, this temptation will be hard to resist.

Previous literature looking at work and flow support the concept that ED overcrowding is primarily related to com-

Table 2. Emergency department (ED) treatment location stratified by triage urgency

\begin{tabular}{|c|c|c|c|c|c|c|}
\hline \multirow[b]{3}{*}{ Location in ED } & \multicolumn{3}{|c|}{ Total no. of patients triaged for each area } & \multirow{3}{*}{$\begin{array}{c}\% \text { for each } \\
\text { area of } 7116 \\
\text { "non-urgent" } \\
\text { patients }\end{array}$} & & \\
\hline & \multirow{2}{*}{$\begin{array}{c}\text { All } \\
\text { patients }\end{array}$} & \multirow[b]{2}{*}{ Urgent* } & \multirow[b]{2}{*}{ Non-urgent* } & & \multicolumn{2}{|c|}{ Admission rate, $\%$} \\
\hline & & & & & Urgent & Non-urgent \\
\hline Ambulant care area & 14768 & 8579 & 6189 & 87.0 & 9.9 & 2.5 \\
\hline Acute-care stretcher area & 4409 & 4207 & 202 & 2.8 & 54.8 & 40.6 \\
\hline Pediatrics area & 2035 & 1652 & 383 & 5.4 & 12.2 & 3.1 \\
\hline Temporary hallway queuet & 1138 & 1021 & 117 & 2.4 & 30.1 & 29.1 \\
\hline Psychiatric interview area & 1044 & 872 & 172 & 2.8 & 39.6 & 18.0 \\
\hline Location unknown & 179 & 126 & 53 & 0.7 & 6.3 & 1.9 \\
\hline Totals & 23573 & 16457 & 7116 & 100.0 & 24.4 & 4.4 \\
\hline
\end{tabular}


plex patients who require ED stretchers, and the loss of stretcher capacity that is created by the "boarding" of inpatients in the ED. ${ }^{16-25}$ In fact, Figure 1 shows that 8579 of the 14768 patients (58\%) sent to the ambulant care area with its limited nursing coverage were in the higher urgency group and produced 852 admissions in spite of the "fasttrack" nature of the ambulant care area's facilities, revealing that this area serves as a needed overflow for urgent as well as non-urgent patients. On the opposite side of the equation, Figure 1 also shows that 202 patients were triaged to acute-care stretchers despite being classed as non-urgent. Eighty-two of these "non-urgent" patients were actually ill enough to require admission; therefore the true potential net savings (of valuable acute-care stretcher and nursing resources) that could have been realized by triaging non-urgent patients away may be closer to 120 stretchers $(2.7 \%$ of 4409$)$.

The main concern related to ED overcrowding is not the number of patients physically in an ED; it is access block - the delay in providing access to necessary acute care. The average waiting times (to reach a treatment space) of 43 minutes for non-urgent patients and 67 minutes for urgent patients may not seem impressive, but the 90th percentile waiting times show a more dramatic difference (100 v. $200 \mathrm{~min}$ ). Most analyses of waiting times in health care are based on averages, in spite of the fact that this statistic is notoriously insensitive to queuing problems. Since queuing pressures always begin in the tail of the time distribution, analysis by percentiles is a much more sensitive way to monitor crowding problems, and the fact that $10 \%$ of urgent and emergent patients (CTAS Levels II and III) waited more than 3.3 hours to reach a treatment location is cause for concern.

\section{Study limitations}

The data presented in this study comes from only one insti-

\begin{tabular}{|c|c|c|c|}
\hline $\begin{array}{l}\text { Treatment } \\
\text { location }\end{array}$ & $\begin{array}{l}\text { No. of } \\
\text { patient visits } \\
\text { with valid } \\
\text { entry times* }\end{array}$ & $\begin{array}{l}\text { Average } \\
\text { wait, min }\end{array}$ & $\begin{array}{c}\text { 90th } \\
\text { percentile } \\
\text { for waits, } \\
\text { min }\end{array}$ \\
\hline $\begin{array}{l}\text { "Acute-care" } \\
\text { stretcher casest }\end{array}$ & 4986 & 67 & 200 \\
\hline $\begin{array}{l}\text { All non-stretcher } \\
\text { cases }\end{array}$ & 17402 & 43 & 100 \\
\hline
\end{tabular}

$* 95 \%$ of all patient visits had valid entry times for which waits could be calculated.

tStretcher cases included those held on the ambulance stretcher and under the care of an emergency medical services attendant until an appropriate acute -care stretcher was available. tution. Although the concepts remain valid and we believe they reflect the reality of most busy EDs, the actual numbers should not be extrapolated to EDs with different patterns of patient acuity. Because the duration of time spent in stretchers is not examined, the study does not measure actual stretcher resources used, only the number of stretchers accessed. However, the bias this produces tends to overestimate the potential for improvement on ED flow that would result from the removal of lower acuity patients, because less ill patients can be expected to occupy a stretcher for less total time than those who are more ill.

This study does not show what the cause of ED access block (overcrowding) is. It does, however, suggest that non-urgent patients are not a large component of the problem, and it is difficult to avoid the obvious conclusion that EDs will be unable to provide timely access for sick patients until the problem of egress of admitted patients is solved. In the meantime, the attempted diversion of nonurgent patients from the ED remains a risk-laden activity with little potential to improve access for the sickest patients.

\section{Conclusion}

Non-urgent patients consume a small fraction of the ED stretchers and acute-care resources; therefore strategies aimed at diverting non-urgent patients are unlikely to improve access for more urgent patients. Using the CTAS to identify patients for diversion away from the ED is measurably unsafe and would lead to inappropriate refusal of care for many patients requiring hospital treatment.

Competing interests: None declared.

\section{References}

1. Canadian Association of Emergency Physicians and National Emergency Nurses Affiliation. Joint Position Statement on emergency department overcrowding [policy]. Can J Emerg Med 2001;3(2):82-4.

2. Canadian Association of Emergency Physicians and the National Emergency Nurses Affiliation. Joint Position Statement. Access to acute care in the setting of emergency department overcrowding [policy]. Can J Emerg Med 2003;5(2):81-6.

3. Graff L. Overcrowding in the ED: an international symptom of health care system failure. Am J Emerg Med 1999;17:208-9.

4. Derlet R, Richards J, Kravitz RL. Frequent overcrowding in US emergency departments. Acad Emerg Med 2001;8:151-5.

5. Schull MJ, Szalai JP, Schwartz B, Redelmeier DA. Emergency 
department overcrowding following systematic hospital restructuring: trends at twenty hospitals over ten years. Acad Emerg Med 2001;8:1037-43.

6. Decter MB: Four strong winds: understanding the growing challenges to health care. Toronto (ON): Stoddart Publishing Ltd; 2000.

7. Crowding Resources Task Force, American College of Emergency Physicians. Responding to emergency department crowding: a guidebook for chapters. Dallas (TX): The College; Aug 2002. Available: www.acep.org/1,5238,0.html (accessed 2004 July 27).

8. Derlet RW, Kinser D, Ray L, Hamilton B, McKenzie J. Prospective identification and triage of nonemergency patients out of an emergency department: a 5-year study. Ann Emerg Med 1995;25:215-23.

9. Washington DL, Stevens CD, Shekelle PG, Baker DW, Fink A, Brook RH. Safely directing patients to appropriate levels of care: guideline-driven triage in the emergency service. Ann Emerg Med 2000;36:15-22.

10. Beveridge R, Clarke B, Janes L, Savage N, Thompson J, Dodd G, et al. Canadian Emergency Department Triage and Acuity Scale: implementation guidelines. Can J Emerg Med 1999;1(3 Suppl). Online version available at: www.caep.ca/002.policies/002-02 .ctas.htm (accessed 10 Aug 2004).

11. Jiménez JG, Murray MJ, Beveridge R, Pons Pons J, Cortés EA, Ferrando Garrigós, et al. Implementation of the Canadian Emergency Department Triage and Acuity Scale (CTAS) in the Principality of Andorra: Can triage parameters serve as emergency department quality indicators? Can J Emerg Med 2003;5(5): $315-22$

12. Manos D, Petrie DA, Beveridge RC, Walter S, Ducharme J. Interobserver agreement using the Canadian Emergency Department Triage and Acuity Scale. Can J Emerg Med 2002;4(1):16-22.

13. Grafstein E, Innes G, Westman J, Christenson J, Thorne A. Interrater reliability of a computerized presenting-complaint-linked triage system in an urban emergency department. Can J Emerg Med 2003;5(5):323-9.

14. Gill JM, Reese CL 4th, Diamond JJ. Disagreement among health care professionals about the urgent care needs of emergency department patients. Ann Emerg Med 1996;28:474-9.

15. Young GP, Wagner MB, Kellermann AL, Ellis J, Bouley D. Ambulatory visits to hospital emergency departments. Patterns and reasons for use. 24 Hours in the ED Study Group. JAMA 1996;276(6):460-5.

16. Schull MJ, Slaughter PM, Redelmeier DA. Urban emergency department overcrowding: defining the problem and eliminating misconceptions. Can J Emerg Med 2002;4(2):76-83.

17. Baumann BM, Chansky ME, Boudreaux ED. Holding admitted patients in the emergency department is most highly correlated with longer patient throughput times. Acad Emerg Med 2004; 11:453.

18. Richardson DB. The access-block effect: relationship between delay to reaching an inpatient bed and inpatient length of stay. Med J Aust 2002; 177:492-5.

19. Trzeciak S, Rivers EP. Emergency department overcrowding in the United States: an emerging threat to patient safety and public health. Emerg Med J 2003;20:402-5.

20. Bazarian JJ, Schneider SM, Newman VJ, Chodosh J. Do admitted patients held in the emergency department impact the throughput of treat-and-release patients? Acad Emerg Med 1996;3:1113-8

21. Forster AJ, Stiell I, Wells G, Lee AJ, van Walraven C. The effect of hospital occupancy on emergency department length of stay and patient disposition. Acad Emerg Med 2003;10:127-33.

22. Dunn R. Reduced access block causes shorter emergency department waiting times: an historical control observational study. Emerg Med 2003;15:232-8

23. Estey A, Ness K, Saunders LD, Alibhai A, Bear RA. Understanding the causes of overcrowding in emergency departments in the Capital Health Region in Alberta: a focus group study. Can J Emerg Med 2003;5(2):87-94.

24. Espinosa G, Miro O, Sanchez M. Effects of external and internal factors on emergency department overcrowding. Ann Emerg Med 2002;39:693-5.

25. Schull M. Emergency department contributors to ambulance diversion: a quantitative analysis Ann Emerg Med 2003;41:467-76.

Correspondence to: Dr. Les Vertesi, Institute for Health Research and Education, Rm. 2820, West Mall Centre, Simon Fraser University, Burnaby BC V5A 1S6; les_vertesi@sfu.ca 